\title{
The Competitiveness of an Institution of Higher Education Through a Reorientation Model
}

\author{
Jorge Enrique Leonardo Gutiérrez de Velasco Rodríguez ${ }^{1}$, Dr. Josefina Morgan Beltrán*, Dr. \\ León Martín Cabello Cervantes ${ }^{3}$

\begin{abstract}
${ }^{I}$ Electronics engineer and student of the Master of Administration with a specialty in Senior Management campanas s/n university city ORC ID: 0000-0001-9619-4193

${ }^{2}$ Doctor of Administration and research professor at the Autonomous University of Querétaro, MEXICO. Belonging to SIN 1, ORC ID: 0000-0002-6338-6209

${ }^{3}$ Doctor and research professor at the Autonomous University of Querétaro, MEXICO. Belonging to SIN 1, ORC ID: 0000-0002-7087-4390
\end{abstract} \\ Faculty of Accounting and Administration of the Autonomous University of Querétaro, MEXICO Cerro de las
}

*Corresponding Authors: Dra. Josefina Morgan Beltrán, Doctor of Administration and research professor at the Autonomous University of Querétaro, MEXICO. Belonging to SIN 1, ORC ID: 00000002-6338-6209

\begin{abstract}
The research addresses from an innovative perspective the permanent concern of the Universities and Institutions of Higher Education in Mexico about how to readapt or reinvent themselves to achieve impact on society in a more effective way through their teaching, research and extension functions? In this qualitative documentary research, characteristics are identified around a proposed categorization that, through the research in the office for the case of public Higher Education Institutions in the state of Querétaro, Mexico, allows to put the first step towards a development deeper and more conclusive posterior for your competitiveness.
\end{abstract}

Keywords: Institutions of Higher Education in Mexico, Models for the creation of Educational Institutions, High Performance Organizations.

JEL: $M 1, O 3$

\section{INTRODUCTION}

The great variety of public and private Higher Education Institutions (HEI) that make up the Higher Education System in Mexico have managed to provide, for more than a century, the vast majority of professionals who have built Mexico since the 19th century. to the present. Today, many of these institutions have evolved, and in a great majority of cases they have shaped and consolidated their teaching mystique embodied in their Educational Model; they have established regulatory frameworks that govern and guide them, and they have emerged as large organizations with administrative and financial dynamics worthy of comparison with any major international consortium.

At the end of the last millennium, during the 1990s, the emergence of new educational, regulatory and administrative models allowed the way in which the educational offer for the population of age to aspire to higher education to evolve. With the creation of the Technological Universities and the Polytechnic Universities, a new line of institutions gave way to the new paradigms of proximity to the productive and economic sectors of the institutions' area of influence, that is, the way in which the HEIs they related to their environment to make their substantive function relevant. (Rubio, 2006)

However, the globalization phenomenon has increasingly demanded that institutions find mechanisms, regulated or not, to support their activity, enrich it and make it socially relevant and responsible with its environment. This is why the identification of those characteristics or attributes that some institutions, within the Universe of HEIs that make up the Mexican Higher Education System, constitutes an important paradigmatic challenge that can undoubtedly allow to identify the evolutionary trend of HEIs in Mexico and for that matter. consequently the reaffirmation of the impact of its substantive functions, or the need for its reorientation. 
The ability of Mexican Institutions to adapt to the vertiginous changes of the new industrial and technological sectors has constituted a great challenge for the definition of institutional policies that privilege the connection and proximity of their substantive functions with the reality of their area of influence and that allow, among other things, to train professionals with the skills and abilities necessary to face the challenges of the globalized world.

With all these premises, the creation of new institutions and the reorientation of existing ones, represents a great challenge for all levels of government, their Educational, Regulatory and Administrative or Management Models, constitute a platform, whose capacity to sustain social demands of its environment, it must be continually put to the test.

There are HEIs with certain attributes in their Educational, Normative and Organizational Models that contribute more faithfully than other institutions to the development of economic sectors.

The objective is to identify those characteristics of the Educational Model, the Regulatory Framework or Model and the Organizational Model of the Institutions to model the best practices and define or propose a "Reorientation Model of HEIs" that allows them to be more competitive and to be located in the new current affairs required by globalization.

\section{BIBLIOGRAPHIC REVIEW}

The Higher Education System in Mexico is characterized by the heterogeneity and diversity of institutions that comprise it, this can be understood from different perspectives; one of these perceiving the variety, size and peculiarities of its members; another for the educational modalities of training or educational levels in which their educational offer is classified according to the International Standard Classification of Education (ISCED 2011) of the United Nations Educational, Scientific and Cultural Organization (UNESCO).

Additionally, there is a classification or typology in terms of the nature of its educational offer and the functions that are carried out in it based on the classification that the National Association of Universities and Institutions of Higher Education (ANVIES) developed in 1999.

\subsection{Educational Model}

The educational model is the teaching mystique of a higher education institution. In this mystique, the dimensions on which competencies and abilities will be developed for the integral formation of individuals are defined. In short, the Educational Model is that set of attributes in its teaching methods that make institutions "unique" and that characterize them in the way they impart or transmit knowledge, but also in the way they generate it; described by Luengo (2003) to say for the Universities their greatest challenge is "with what educational content, with what pedagogical strategies, with what type of university organization, with what purpose or social aspiration and in what direction should this growth occur".

In these Educational Models, institutions can establish, in their simplest form, attributes or characteristics with which they will develop the educational processes, the evaluation of the training, the quality of the training, and the educational goals in terms of social recognition or impact on the individuals who participate in the training processes. In the most complex form, Guiding Axes are established in which axioms of operation are grouped, of transversality in the institutions in terms of the dimensions with which they wish to train individuals.

\subsection{Administrative or Management Model}

They are the organizational characteristics that HEIs use for their operation based on their educational model.

In relation to their organization model, the HEIs in the entity present a classification that is reduced to the type of legal body they comprise, that is, there are both identified institutions and Decentralized Public Organizations of the State Government and Institution whose organization and governance is defined by independently.

For these two classifications there are regulations that largely determine the type of organization and how it will function at the time of the exercise of its financial resources and then its effectiveness, efficacy and efficiency at the time of carrying out its substantive functions. 


\subsection{Legal Model or Regulatory Framework}

Since they are created, Mexican public educational institutions have emerged limited by a legal and normative framework, a framework of action that starts from the Political Constitution of the United Mexican States, including the General Law of Education of the Federal Ministry of Public Education and all sorts of regulations and laws that in a great majority of the times will permanently mark institutional life.

According to Escotet (2005), the legislative and regulatory body of the Institutions at present is a major obstacle to the permanent adaptation process to which any Educational Institution is subjected. $\mathrm{He}$ also affirms that, the greater the amount of university legislation, the greater the difficulty for the flexibility, diversification and innovation of its structures.

Flexible legislation goes hand in hand with flexible administration. The great challenge then is how to build flexible legislation if it is always subject to existing laws, state or federal, which naturally restrict and immobilize institutions from their birth.

The research axes related to the Educational, legal and Administrative and Legal Models (ELA Model), present relationships and interdependencies that can well be raised in an equation, where they can integrate a matrix of correlations and interdependencies to propose an ELA Model whose maximization in terms of Efficiency and effectiveness can also be calculated.

If it is then considered that the values of said correlation matrix are interpreted ELA characteristics or elements within the respective Educational, Legal and Administrative (ELA) models that the institutions can have, create or modify, the initial work then falls on making a identification and definition of those characteristics that make Higher Education Institutions have a high impact.

\subsection{Characteristics of the Educational Model}

In the case of HEIs, there is a series of common elements or parameters that, because they belong to the public system of higher education in Mexico, must be met or addressed invariably. Here is a brief description of its importance.

\subsubsection{Efficiency}

The efficiency of HEIs today is measured mainly by the number of students graduating from a university program vs. the number of students who entered the respective generational cohort. The national average is $39 \%$ efficient, according to ANUIES.

\subsubsection{Evaluation}

One characteristic that largely determines access to extraordinary financing and that mainly allows for elements for continuous improvement is evaluation. Since the integration of the National Commission for the Evaluation of Higher Education by the National Association of Universities and Institutions of Higher Education (ANUIES) in 1989, the evaluation has remained an axis that allows determining, with increasing methodological certainty, the improvement it continues as an everyday university process.

\subsubsection{Relevance}

This attribute is perhaps the most challenging of all that the evaluation not only of efficiency but also of effectiveness represents for HEIs. The relevance is closely linked to the curricular contents (ANUIES, 2004) of the study programs offered by the institutions and implies great medium and long-term efforts to be able to have a certain degree of relevance in the study plans and programs, but It is also true that this is again limited to what they should and can do in their particular framework of action (Gómez, 2009). The relevance in plain words is understood as that attribute that the training processes of the institutions have to train their students and prepare them for the immediate work reality, that is, teach theories, techniques and current knowledge according to the reality of their environment.

\subsubsection{Bonding}

The link until a few years ago was a paradigm for universities, and this was limited in the best of cases to the initial or final approach processes that university students had with the productive sector 
throughout their educational journey (visits, conferences, practices, etc.). Today, bonding is also considered a substantive university function (Rubio 2006) and must also be understood from a broader sense; Linking is a channel through which HEIs can permanently provide feedback on their actions and impact on society.

\subsubsection{Quality}

The Evaluation attribute mentioned above is undoubtedly closely related to Quality. There are two perspectives, the first of them is to have the institutional administration approach with a process approach that allows or makes it susceptible to "certify" under certain standards of quality management systems, to the institutions; and I am referring very in particular to the ISO 9000 or Total Quality models. The other approach is the most interesting, how to define educational quality; This definition with more or less elements can be defined as everything that the IES develops before, during and after the educational journey of its students to guarantee a prompt and effective insertion into the labor market by a significant percentage of its graduates. For which, the Interinstitutional Committees for the Evaluation of Higher Education (CIEES) were created, which are made up of academic pairs that under certain criteria evaluate HEIs and categorize them into three possible levels, which allows institutions to propose schemes planning to move from one level of compliance to another (Rubio 2006).

\subsection{Characteristics of the Legal Model}

Considering the universe of HEIs in this research work, they can be classified into those that were created from a Decree issued by the local legislative body and the existence of an Autonomous University with legislation and autonomy legally declared with the endorsement of the government of the condition.

Regarding the decrees for the creation of two of the entity's HEIs, it follows that they have:

a) Government and administrative bodies made up of state and federal officials in equal proportion, where the responsibilities of making academic and administrative decisions of high impact of the institution fall.

b) They define their academic performance in terms of methodologies or processes that are sometimes restrictive for the design of their study plans and programs.

c) They clearly define their framework of university action, their corporate purpose, substantive functions and the area of influence they will serve with their university services.

d) They clearly establish the processes through which the institution governs itself, but always under the supervision of those who finance it.

\subsection{Characteristics of the Administration Model}

Framed in their regulations and in those relating to the sectorization to which they have been subjected, HEIs have a highly conditioned freedom to define their own organizational structures and frameworks. With this idea, the possibility of proposing innovative organizational structures is limited to those existing models or schemes in public administration, which tends at an early age to gradually bureaucratize institutions.

From the information collected, it is observed that the HEIs analyzed have

a) Organizational structures subject to the budgets and salary tables of the state public administration.

b) Legal-administrative structures, that is, regulations that slow down the exercise of public resources to develop substantive institutional functions.

c) They do not have explicit models for the development of their own income, that is, without this being the end, it may well become a means to finance university activities of a very diverse nature, which can undoubtedly have a more forceful impact on its environment.

\section{Methodological DeSign}

The methodology that was used to approach the object of study is qualitative through the case study and phenomenology methods, which is the interpretation of the interviewees on the subject of study, using the techniques of observation, semi-structured interviews in depth made to experts on the 
subject and documentation analysis, the responses of the managers with the analyzed documentation and the perception of the second-level managers were analyzed through triangulation. In the first place, an approach was provoked with the public HEIs identified in the entity to know in a first step the degree of willingness to share their experiences and guidance on their regulatory framework, documented substantive processes and educational mystique. The results were partially positive and even allowed reorienting the documentary research in this work.

Through the qualitative approach, phenomena can be approached under the context of their environment and the interpretation as a whole allows deepening the ideas, realities in a broader way, which is equally necessary due to the complexity that the study of the Institutions of Higher Education as social entities.

With this approach, a fundamentally documentary research is developed in a concrete way, using not only a bibliographic review process but also an analysis of normative documents that can be accessed to develop this work, understanding documentary research as one that uses sources information of various kinds for the collection of data, facts, studies or experiments and from which new studies or interpretations necessary for the research processes can be launched (Sierra, 1999)

\section{Research Problem}

The set of Public Higher Education Institutions in Mexico is made up of a great variety of organizations whose typology and educational models (Rubio, 2006), allow offering a very important amount of University Educational Programs (PE's) available throughout of the national territory. These organisms have impacts on their environments that can be identified in a first instance, analyzed in a second and modeled in a third.

The series of questions that allow delineating and temporarily delimiting the research space are:

a) How is the success or impact of a public HEI defined in Mexico?

b) What makes HEIs last and have an impact on their environment or area of influence

c) What is the Management model of an HEI that adequately supports the substantive processes of the institution, that seeks its efficiency, transparency and effectiveness in the use of its resources (public or private) and that promotes a sustainable financial viability in the long term?

Then, is it possible to identify, in terms of their Educational, Legal and Administrative models (ELA Model, for the purposes of this research), those institutions that have a clearly identified impact on their environment? Is it also possible to know the characteristics of these models, in such a way that a reproducible model for the creation and reorientation of HEIs in Mexico can be proposed later?

\section{Research objectives}

The general objective of this exploratory research work is to identify those characteristics and elements of the Educational, Legal and Administrative Models in Higher Education Educational Institutions that allow proposing a parameterization of said ELA model for HEIs in Querétaro, however, a series of particular objectives must be clarified to start the research process.

\section{Research questions}

How can the long-term impact of an HEI be determined?

\section{Hypothesis}

"The long-term impact of an HEI can be determined to a large extent by the flexibility of operation of its Educational-Legal-Administrative Model (ELA) in the face of new social and economic challenges and how this Model is articulated with said socioeconomic reality"

"It is possible to identify characteristics in the Educational, Legal and Administrative Model of an HEI that allows generating a" Model of Creation and reorientation of HEIs "that can turn them into lasting and high-impact institutions"

\section{Justification}

The main consideration regarding the impact of this exploratory research is to carry out a "parameterization" exercise of the characteristics, elements or attributes of the HEIs in Querétaro to 
have arguments so that the state educational authorities can authorize a more in-depth investigation and that allows the identification of new models of evaluation of the management and impact of an HEI and consequently to raise new opportunities for reorientation or adaptation of HEIs.

\section{DISCUSSION}

This investigation allowed obtaining several results, in a first classification those that will allow supporting the subsequent investigation and in a second classification, those related to the investigation itself.

In relation to the research itself, characteristics of both the Educational, Legal and Administrative Models of three of the 4 HEIs that were studied were identified, without this being conclusive, that is, the need to continue making a review is distinguished However, there is an important correlation and interdependence between the different characteristics of the Educational, Legal and Administrative Models in Higher Education Educational Institutions that allow to propose a parameterization of said ELA model for HEIs in Mexico.

\section{PROPOSAL}

At the conclusion of this initial research work, it is proposed (Figure 1):

1. A model that shows the relationship between the Educational-Legal-Administrative (EJA) models of an HEI that, when effectively identified, would allow the identification of the impact of said HEI on Society.

2. Generate a communication link between the different Institutions that allows the use of the achievements of one and the other in a collaborative environment that enriches all those involved.

3. Likewise, access other levels of management to improve administrative practices in HEIs.

4. The proposal of public policies is suggested with the aim of generating a joint work between the University in the research aspect, such as the Government, in aspects of support and resources and the Companies for support and sponsorship and with the participation of each sector They will enrich the results and the contribution to science and the improvement of the Country.

Figure1. Proposed Model

\begin{tabular}{|c|c|c|c|c|}
\hline \multirow[t]{2}{*}{$\begin{array}{l}\text { OBSERVATI } \\
\text { ON } \\
\text { Obvious and } \\
\text { Hidden } \\
\text { Obstacle } \\
\text { Opinion } \\
\text { Option } \\
\text { Operation } \\
\text { Optimization } \\
\text { Obligation } \\
\text { CHANCE } \\
\text { (Kairos) } \\
\end{array}$} & $\begin{array}{l}\text { "EJA" } \\
\text { MODEL } \\
\text { OF AN IE } \\
\text { EJA Model: } \\
\text { Educational- } \\
\text { Legal- } \\
\text { Administrati } \\
\text { ve }\end{array}$ & $\begin{array}{l}\text { Model FLEX-INNO } \\
\text { (FLEXIBLE-INNOVATIVE) } \\
\text { Relevant, Flexible, Open } \\
\text { Closelylinked } \\
\text { BasedonInfluentialCompetenci } \\
\text { es }\end{array}$ & $\begin{array}{l}\text { OPPORTUNITY } \\
\text { (CONFUSION) } \\
\text { Social comunication } \\
\text { Management } \\
\text { Challenges } \\
\text { Strategy } \\
\text { Governmentsupport }\end{array}$ & $\begin{array}{l}\text { LONG-TERM } \\
\text { SUSTAINABILITY } \\
\text { (RENEWAL) } \\
\text { Financial autonomy } \\
\text { Influenceonyourenvironme } \\
\text { nt } \\
\text { Generator of Knowledge } \\
\text { and wealth }\end{array}$ \\
\hline & \multicolumn{2}{|c|}{$\begin{array}{l}\text { RESTRA } \\
\text { (REStrictive-TRAditional) } \\
\text { Educational model focused on teaching } \\
\text { Regulations and restrictivegoverningbodies } \\
\text { Unionswithbroadpower }\end{array}$} & $\begin{array}{l}\text { OBSOLECENCE } \\
\text { (DENIAL- } \\
\text { COMPLACENCE) } \\
\text { Fear } \\
\text { Unawareness } \\
\text { Distrust }\end{array}$ & $\begin{array}{l}\text { CONFLICT } \\
\text { (COMPLACENCE- } \\
\text { DENIAL) } \\
\text { Impotence } \\
\text { incongruity }\end{array}$ \\
\hline \multirow{2}{*}{\multicolumn{3}{|c|}{$\begin{array}{l}\text { MODEL OF CREATION AND REORIENTATION OF HEI } \\
\text { IN MEXICO, THROUGH ITS ARTICULATION WITH THE } \\
\text { ECONOMIC AND SOCIAL SECTORS } \\
\text { HYPOTHESIS } \\
\text { The long-term impact of an HEI can be determined by the } \\
\text { flexibility of operation of its Educational-Legal-Administrative } \\
\text { Model in the face of new social and economic challenges and how } \\
\text { this model is articulated with said socioeconomic reality. }\end{array}$}} & $\begin{array}{l}\text { LOW } \\
\text { PublicPolicyGenerat } \\
\text { or } \\
\text { Efficient }\end{array}$ & $\begin{array}{l}\text { TRANSCENDENT } \\
\text { Replicable } \\
\text { PublicPolicyGenerator } \\
\text { Efficient }\end{array}$ \\
\hline & & & \multicolumn{2}{|c|}{$\begin{array}{l}\text { IMPACT } \\
\text { Successful graduates (Employees / Entrepreneurs) } \\
\text { Scientific and Technological } \\
\text { Social and Cultural Influence } \\
\text { Social responsability } \\
\text { Costeffectiveness }\end{array}$} \\
\hline
\end{tabular}




\section{INTEREST \\ Imagination / Information / Ideas / Exchange / Investment / Implementation / Impact \\ INNOVATION (Kairos))}

\section{CONCEPTUALIZATION OF THE HEURISTIC MATRIX (interpretation)}

ClaesJaenssen's Four Rooms of Change Concept can be adapted to the diagnosis of an HEI to identify the impact it has on society, within a frame of reference defined by its ELA Model.

Considering the above, based on the impact of an HEI and its identification of the ELA Model, it can be diagnosed in what state it is: in a CONFLICT situation in which the institution may have a certain degree of favorable or even transcendent impact, but that its RESTRA-type ELA model, in which its regulations, adaptability and organizational structure are restrictive and traditional and inhibit or slow down development. A similar reasoning is identified for the other rooms or stadiums in which an IES can be found and over which it should travel according to its environment to seek RENEWAL or long-term sustainability, whatever the definition that the institution wants to adopt.

\section{REFERENCES}

[1] ANUIES, Higher Education in the XXI Century, Strategic lines of development, A proposal from ANUIES, March 2004

[2] Escotet Miguel Angel, Contemporary forms of university government and administration: historical and prospective vision, PerfilesEducativos Magazine, October 2004

[3] Gómez Camarena Beatriz Olivia, Higher Education and the Labor Market: linkage and social relevance, why? And whatfor ?, Centro de Investigación en Alimentos y Desarrollo A.C., 2010

[4] Latin America and the Caribbean (IESACC) and Colombian Association of Universities (ASCUN). Retrieved April 26, 2011, from http://www.anuies.mx/e_proyectos/pdf/ 04_Las_reformas_en_la_Educacion_Superior_en_Mexico.pdf

[5] LII Legislature of the Free and Sovereign State of Querétaro de Arteaga, Decree creating the Technological University of Querétaro, La sombra de Arteaga, 1994

[6] Luengo González, E. (2003). Trends in higher education in Mexico: a reading from the perspective of complexity. Seminar on Higher Education Reforms in Latin America and the Caribbean; June 5-6, 2003, Bogotá, Colombia;

[7] LV Legislature of the Free and Sovereign State of Querétaro de Arteaga, Decree creating the National Aeronautical University in Querétaro, La sombra de Arteaga, 2007

[8] Rubio Oca, Julio (Coord.). Educational Policy and Higher Education in Mexico. 1995-2006: A balance / coord. Julio Rubio Oca. - Mexico: FCE, SEP, 2006

[9] Sampieri Hernández Roberto, Research Methodology 4th Edition, Ed. McGraw Hill Interamericana, 2006

[10] SEP-GEQ, Coordination Agreement for the Creation, Operation and Financial Support of the Technological University of Querétaro, February 4, 1994

[11] SEP-GEQ, Coordination Agreement for the Creation, Operation and Financial Support of the National Aeronautical University in Querétaro, September 29, 2007

[12] Sierra Bravo, Restituto. Dissertations and scientific research; general methodology of its preparation and documentation. Madrid: Paraninfo, 1999.

[13] United Nations Educational, Scientific and Cultural Organization (UNESCO), International Standard Classification of Education ISCED, 20111997, DecMAY 201206 


\section{AUTHORS' BIOGRAPHY}

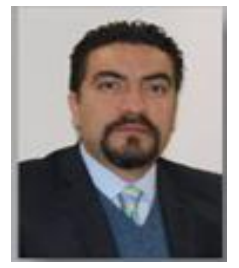

Jorge Enrique Leonardo Gutiérrez de Velasco Rodríguez,

BSc. In Electronics from Instituto Tecnológico de Querétaro, 1993

Master of Instrumentation and Control credits, Universidad Autónoma de Querétaro, 1999

Currently, coursing Senior Management MBA, Universidad Autónoma de Querétaro, 2014

Metrologist at the National Metrology Center (CENAM) in 1994. At technology services department I developed electronic systems and equipment for high precision measurements.

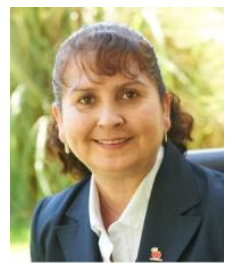

Dr. Josefina Morgan Beltrán, Research Professor of the Autonomous University of Querétaro, head of the postgraduate division of the Faculty of Accounting and Administration, Doctor of Administration with post-doctorate in Education, member of the National System of Researchers level I (SNI), member of the Program for Professional Development Teacher (PRODEP) and the National Association of Accounting and Administration Faculties and Schools (ANFECA).

Citation: Jorge Enrique Leonardo Gutiérrez de Velasco Rodríguez, et. al, "The Competitiveness of an Institution of Higher Education Through a Reorientation Model" International Journal of Managerial Studies and Research (IJMSR), vol 9, no. 4, 2021, pp. 24-31. doi: https://doi.org/10.20431/2349-0349.0904003.

Copyright: () 2021 Authors. This is an open-access article distributed under the terms of the Creative Commons Attribution License, which permits unrestricted use, distribution, and reproduction in any medium, provided the original author and source are credited. 